\title{
Viabilidade e germinação de embriões de oliveira submetidos a diferentes condições de armazenamento de frutos
}

\author{
Rafaeli Aparecida Vieira de Souza(1), Francyane Tavares Braga(2), João Vieira Neto(3), \\ Elisabeth Aparecida Furtado de Mendonça(1), Patrícia Helena de Azevedo(1) \\ e Geraldo Magela de Almeida Cançado(2)
}

\begin{abstract}
(1) Universidade Federal de Mato Grosso, Faculdade de Agronomia e Medicina Veterinária Avenida Fernando Correa, s/no, CEP 78060-900 Cuiabá, MT. E-mail: rafaeli_vieira@hotmail.com, beth@ufmt.br, patriciaazevedo@cpd.ufmt.br (2)Empresa de Pesquisa Agropecuária de Minas Gerais, Laboratório de Biotecnologia Vegetal, Avenida Santa Cruz, o 500, CEP $37780-000$ Caldas, MG. E-mail: ftbraga@yahoo.com.br, gcancado@gmail.com ${ }^{(3)}$ Empresa de Pesquisa Agropecuária e Extensão Rural de Santa Catarina, Estação Experimental de Ituporanga, Estrada Geral, no 453, Caixa Postal 121, CEP 88400-000 Ituporanga, SC. E-mail: joaoneto@epagri.sc.gov.br
\end{abstract}

Resumo - O objetivo deste trabalho foi avaliar o efeito de diferentes condições de armazenamento na preservação da viabilidade e da germinação de embriões zigóticos de oliveira. Utilizou-se o delineamento inteiramente casualizado, em esquema fatorial $4 \times 2$. Frutos da cultivar Santa Catalina foram submetidos a diferentes condições de armazenamento - saco plástico em geladeira a $4-5^{\circ} \mathrm{C}$ e $15 \%$ de umidade relativa (UR), dessecador em geladeira a $4-5^{\circ} \mathrm{C}$ e $12 \%$ UR, saco plástico em laboratório a $27 \pm 1^{\circ} \mathrm{C}$ e $55 \% \mathrm{UR}$, dessecador em laboratório a $27 \pm 1{ }^{\circ} \mathrm{C}$ e $30 \%$ UR - e aos períodos de armazenamento de 30 e 120 dias. A germinação in vitro e a viabilidade foram avaliadas pelo teste de tetrazólio aos 30 e 120 dias de armazenamento. A maior taxa de germinação $(91,66 \%)$ e de viabilidade $(33,33 \%)$ foram observadas a $4-5^{\circ} \mathrm{C}$ e $12 \%$ UR, aos 30 dias. Esta condição de armazenamento preserva os frutos de oliveira por mais tempo.

Termos para indexação: Olea europaea, fisiologia de sementes, germinação in vitro, teste de tetrazólio.

\section{Viability and germination of olive embryos subjected to different conditions of fruit storage}

\begin{abstract}
The objective of this work was to evaluate the effect of different storage conditions on the preservation of the viability and germination of olive zygotic embryos. A completely randomized block design was used, in a $4 \times 2$ factorial arrangement. Fruits of the cultivar Santa Catalina were subjected to different storage conditions - plastic bag in refrigerator at $4-5^{\circ} \mathrm{C}$ and $15 \%$ relative humidity $(\mathrm{RH})$, dissector in refrigerator at $4-5^{\circ} \mathrm{C}$ and $12 \% \mathrm{RH}$, plastic bag at laboratory room at $27 \pm 1^{\circ} \mathrm{C}$ and $55 \% \mathrm{RH}$, dissector in laboratory room at $27 \pm 1{ }^{\circ} \mathrm{C}$ and $30 \% \mathrm{RH}-$, and to storage periods of 30 and 120 days. In vitro germination and viability were evaluated by the tetrazolium test at 30 and 120 days of storage. The highest germination rate $(91.66 \%)$ and viability (33.33\%) were observed at $4-5^{\circ} \mathrm{C}$ and $12 \% \mathrm{RH}$ at 30 days. This storage condition preserves olive fruits for longer time.
\end{abstract}

Index terms: Olea europaea, seed physiology, in vitro germination, tetrazolium test.

\section{Introdução}

A oliveira (Olea europaea L.) é uma espécie perene amplamente cultivada e apreciada em todo o mundo, que apresenta grande importância no mercado alimentício. No Brasil, o cultivo da oliveira ainda é incipiente, no entanto, na última década, a área cultivada com pomares comerciais ampliou-se consideravelmente, principalmente em locais cuja temperatura média anual é de 15 a $20^{\circ} \mathrm{C}$.

Uma das grandes limitações para a expansão da olivicultura nacional é a falta de material propagativo na quantidade e na qualidade necessárias para a instalação de novos pomares. Comercialmente, a oliveira é propagada por enxertia e estaquia. A propagação por sementes não é aconselhável em razão do longo período juvenil e da segregação genética, pois a oliveira apresenta polinização cruzada (Binet et al., 2007). Contudo, a propagação por sementes é fundamental para o melhoramento genético dessa espécie e para estudos de avaliações fisiológicas, morfológicas e bioquímicas.

O cultivo de embriões zigóticos em meio artificial e estéril é considerado o modelo ideal para a realização desses estudos, além de possibilitar o resgate de embriões raros, a multiplicação clonal de genótipos 
superiores e a fácil aplicação de tratamentos, tais como exposição a agentes bióticos e abióticos. $\mathrm{O}$ cultivo in vitro também oferece como grande vantagem o melhor controle de fatores ambientais, como composição do meio, temperatura e luminosidade (Roussos \& Pontikis, 2002). Entretanto, a colheita de frutos da oliveira é uma atividade sazonal restrita a poucos meses do ano. No Brasil, esse período começa em janeiro e se estende até o final de março, conforme a variedade (Vieira-Neto et al., 2008). Por se tratar de um período curto, o armazenamento dos frutos é necessário para que o fornecimento de sementes viáveis seja possível durante o ano. Porém, informações acerca da viabilidade dos embriões de oliveira em condições de armazenamento são raras e imprecisas.

Uma forma usualmente empregada em outras espécies vegetais para avaliar a percentagem de embriões potencialmente viáveis é o teste de tetrazólio. Este teste é utilizado como método de rotina por unidades beneficiadoras e armazenadoras, para determinação da qualidade de sementes de milho, soja, feijão, entre outras. O teste de tetrazólio baseia-se na atividade de enzimas desidrogenases nos processos respiratórios dos tecidos. Durante a respiração, ocorre liberação de íons de hidrogênio, com os quais o sal 2,3,5-trifenil cloreto de tetrazólio reage e forma uma substância de cor vermelha e insolúvel, denominada de formazan, nos tecidos vivos da semente (Ministério da Agricultura, Pecuária e Abastecimento, 2009). Na oliveira, não se localizou nenhum relato científico da aplicação do teste de tetrazólio para mensuração da viabilidade de embriões zigóticos.

O potencial fisiológico das sementes e embriões é regido pelo potencial genético de cada espécie ou da mesma variedade. Algumas variedades são menos propensas à deterioração, pois seu progresso é variável entre diferentes espécies, entre lotes de cultivares da mesma espécie, entre lotes da mesma cultivar e entre sementes do mesmo lote (Delouche, 1976). Segundo este autor, o processo de deterioração é caracterizado por degeneração das membranas celulares, alteração dos mecanismos de produção de energia e biossíntese, redução das atividades respiratórias, retardo na germinação e no crescimento das plântulas, redução do potencial de armazenamento, desuniformidade do crescimento e do desenvolvimento das plantas, aumento na susceptibilidade a adversidades ambientais e perda do poder germinativo.
As características da espécie ou da cultivar, como longevidade natural, composição química e diferenças genéticas, aliadas às condições ambientais de armazenamento, podem facilitar ou retardar a redução da velocidade e da intensidade de deterioração.

O objetivo deste trabalho foi avaliar o efeito de diferentes condições de armazenamento na preservação da viabilidade e da germinação de embriões zigóticos de oliveira.

\section{Material e Métodos}

O experimento foi conduzido no Laboratório de Biotecnologia Vegetal da Empresa de Pesquisa Agropecuária de Minas Gerais (Epamig), em Caldas, MG. Foram utilizados frutos da cultivar Santa Catalina, provenientes do banco de germoplasma de oliveira da Fazenda Experimental da Epamig, em Maria da Fé, MG. Os frutos foram coletados após atingirem maturação fisiológica, determinada pela coloração externa do fruto.

Foi realizado teste de germinação in vitro antes da implantação do experimento de armazenamento dos frutos, para verificar a percentagem de germinação dos embriões segundo metodologia descrita por Oliveira (2001).

Foram despolpados 20 frutos de oliveira 'Santa Catalina'. As sementes foram lavadas em água corrente e secas à sombra por 24 horas. Em seguida, realizouse assepsia superficial com álcool a $70 \%$ por $15 \mathrm{~min}$, $\mathrm{e}$, posteriormente, as sementes foram submetidas à temperatura de $3-5^{\circ} \mathrm{C}$ por cinco dias.

As sementes foram rompidas com auxílio de alicate, para extração do embrião. Foi feita assepsia superficial do albúmem em câmara asséptica de fluxo laminar, com álcool a $70 \%$ durante $30 \mathrm{~s}$, e, posteriormente, em hipoclorito de sódio a $1 \%$ por 20 min, seguida por tríplice lavagem em água destilada e autoclavada.

Para o teste de germinação dos embriões, foi utilizado meio MS (Murashige \& Skoog, 1962), acrescido de $30 \mathrm{~g} \mathrm{~L}^{-1}$ de sacarose e $6 \mathrm{~g} \mathrm{~L}^{-1}$ de agar. $\mathrm{O} \mathrm{pH}$ do meio foi ajustado para 5,8 antes da autoclavagem. Os embriões foram submetidos à inoculação no meio MS e, em seguida, incubados em sala de crescimento, com temperatura ajustada para $25 \pm 1{ }^{\circ} \mathrm{C}$, fotoperíodo de 16 horas de luz e irradiância de $36 \mu \mathrm{mol} \mathrm{m}{ }^{-2} \mathrm{~s}^{-1}$ durante 30 dias. O percentual de germinação dos embriões foi acompanhado três vezes por semana e determinado ao final do trigésimo dia. Foram utilizadas quatro 
repetições com cinco embriões, o que totalizou 20 embriões.

Foram selecionados 960 frutos para o experimento de armazenamento, que, após lavados em água corrente, foram secos à sombra por 24 horas e submetidos aos tratamentos de armazenamento: T1, saco plástico em geladeira a $4-5^{\circ} \mathrm{C}$ e $15 \%$ de umidade relativa (UR); $\mathrm{T} 2$, dessecador em geladeira a $4-5^{\circ} \mathrm{C}$ e $12 \% \mathrm{UR}$; T3, saco plástico em laboratório a $27^{\circ} \mathrm{C} \pm 1^{\circ} \mathrm{C}$ e $55 \% \mathrm{UR}$; $\mathrm{T} 4$, dessecador em laboratório a $27 \pm 1^{\circ} \mathrm{C}$ e $30 \% \mathrm{UR}$; e a dois períodos de armazenamento de 30 e 120 dias. Para cada tratamento, foram selecionados 120 frutos. Para o teste de germinação, foram utilizados quatro repetições com cinco embriões, o que totalizou 20 embriões, enquanto para o teste de tetrazólio, foram utilizados quatro repetições com 25 embriões, o que totalizou 100 embriões. Utilizou-se o delineamento experimental inteiramente casualizado em esquema fatorial 4x2, com quatro condições de armazenamento e dois períodos de tempo.

As temperaturas foram obtidas com auxílio de geladeira $\left(4\right.$ a $\left.5^{\circ} \mathrm{C}\right)$ e laboratório $\left(27 \pm 1^{\circ} \mathrm{C}\right)$, e as umidades relativas com recipientes dessecadores com sílica gel. As temperaturas e as umidades relativas foram medidas com termo-higrômetro digital instalado no interior dos ambientes de armazenamento.

Após o período de armazenamento, foi realizado teste de germinação in vitro aos 30 dias e outro teste aos 120 dias, com os mesmos procedimentos descritos anteriormente, de acordo com Oliveira (2001).

Para avaliação da viabilidade dos embriões, realizouse, inicialmente, um teste para determinar a melhor concentração de sal de tetrazólio na solução. Foram utilizadas concentrações de $0,01,0,5$ e $0,75 \%(\mathrm{p} / \mathrm{v}) \mathrm{de}$ sal de tetrazólio em solução aquosa com $\mathrm{pH}$ ajustado para 6,5 .

Após os períodos de armazenamento (30 e 120 dias), o albúmen foi retirado cuidadosamente e os embriões colocados em tubos de ensaio totalmente submersos em solução de tetrazólio a $0,01 \%$. Os tubos foram mantidos no escuro a $30^{\circ} \mathrm{C}$ por 18 horas. Foram utilizadas quatro repetições por tratamento, constituídas por 25 embriões de oliveira, o que totalizou 100 embriões. Após o aparecimento da coloração decorrente da reação com o tetrazólio, os embriões foram lavados em água corrente e submersos em água até o momento da avaliação. A avaliação visual dos embriões foi realizada de acordo com a localização e a intensidade da coloração e a presença de áreas não coradas em regiões essenciais para a viabilidade do embrião (Oliveira et al., 2005). Os embriões foram individualmente classificados em três categorias conforme o padrão de coloração: viáveis (mais de $80 \%$ da superfície do embrião corada com tom rosa acentuado, incluindo eixo embrionário e região de translocação); parcialmente viáveis (menos de $80 \%$ da superfície do embrião corada, incluindo eixo embrionário e região de translocação); e inviáveis (menos de $70 \%$ da superfície do embrião corada ou corada com tom rosa pálido, sem coloração no eixo embrionário e na região de translocação).

Utilizou-se o delineamento experimental inteiramente casualizado, com oito tratamentos e quatro repetições de cinco embriões. Utilizou-se o programa Sisvar 5.0 (Ferreira, 2008) para análise de variância dos testes de germinação in vitro e de viabilidade das sementes. As médias foram comparadas pelo teste de Scott \& Knott, a 5\% de probabilidade. Para avaliação da concordância entre as variáveis analisadas, foi utilizado coeficiente de correlação linear de Pearson.

\section{Resultados e Discussão}

A taxa de germinação dos embriões zigóticos em meio MS foi de $100 \%$, conforme teste inicial para verificar o potencial germinativo in vitro dos embriões de 'Santa Catalina'. Três dias depois da inoculação, foi observado início da abertura e enverdecimento dos cotilédones e, após dez dias, protrusão completa da raiz primária. A alta taxa de germinação e a rapidez nos processos observados devem-se à qualidade fisiológica dos embriões e à alta disponibilidade de macro e micronutrientes, vitaminas e aminoácidos no meio básico MS, além de condições controladas de ambiente.

Diferenças significativas entre as condições de armazenamento dos frutos foram observadas para percentagem de germinação. A maior média de germinação ocorreu no ambiente com UR 12\% e temperatura de 4 a $5^{\circ} \mathrm{C}$ (Tabela 1). No entanto, não houve interações entre as condições e o tempo de armazenamento. Embriões provenientes dos frutos armazenados em UR $55 \%$ e temperatura de $27 \pm 1^{\circ} \mathrm{C}$ não germinaram, independentemente do período de armazenamento. Sementes expostas a temperaturas elevadas por determinado período de tempo podem apresentar idade fisiológica ou grau de deterioração mais avançados que outras armazenadas em ambiente de baixa temperatura e umidade relativa do ar, o que 
pode culminar em queda no percentual germinativo e morte das sementes (Marcos-Filho, 2005). A combinação de baixa temperatura e umidade relativa do ar promoveu maiores percentuais de germinação in vitro, o que já foi observado em outros trabalhos, com outras espécies (Cardoso et al., 2004; Oliveira et al., 2005; Alvarez-Pardo \& Ferreira, 2006).

Os períodos de armazenamento estudados não apresentaram diferenças significativas. O período de 30 dias apresentou o maior valor de média de germinação in vitro $(91,66)$. Porém, a germinação de embriões de frutos armazenados por 30 e 120 dias em condições de $15 \%$ UR e temperatura de 4 a $5^{\circ} \mathrm{C}$ foi de $66,66 \%$ (Tabela 1). Este resultado pode ser um indicativo de que a temperatura baixa possa ter um papel mais relevante na conservação dos embriões do que a UR, embora a combinação de temperatura de 4 a $5^{\circ} \mathrm{C}$ e UR $12 \%$ aos 30 e 120 dias tenha proporcionado germinação de 91,66 e $83,33 \%$, respectivamente, o que indica eficiência da conservação de sementes nesse tratamento.

A perda na capacidade de germinação de embriões, de modo geral, ocorre em razão do tempo de armazenamento da semente, pois a proporção de sementes mais vigorosas decresce com o tempo de armazenamento, o que acarreta variação no potencial fisiológico das sementes e torna sua germinação mais heterogênea (Carvalho \& Camargo, 2003). Os sintomas mais evidentes de deterioração, que podem ser observados durante a germinação e o desenvolvimento inicial das plântulas, são a redução acentuada na percentagem de germinação, a perda do vigor e o aumento da ocorrência de plântulas anômalas.

A concentração de $0,01 \%$ de sal de tetrazólio foi a que produziu melhor padrão de coloração e permitiu a separação dos embriões de oliveira em três grupos. As concentrações de 0,75 e $0,5 \%$ produziram excesso

Tabela 1. Percentagem de embriões de oliveira 'Santa Catalina' germinados in vitro, em diferentes condições de temperatura, umidade relativa do ar e períodos de armazenamento $^{(1)}$.

\begin{tabular}{lccr}
\hline Temperatura & Umidade relativa & \multicolumn{2}{c}{ Período de armazenamento } \\
\cline { 3 - 4 }$\left({ }^{\circ} \mathrm{C}\right)$ & $(\%)$ & 30 dias & 120 dias \\
\hline 4 a 5 & 15 & $66,66 \mathrm{Aa}$ & $66,66 \mathrm{Aa}$ \\
4 a 5 & 12 & $91,66 \mathrm{Aa}$ & $83,33 \mathrm{Aa}$ \\
$27 \pm 1$ & 55 & $0,00 \mathrm{Ca}$ & $0,00 \mathrm{Ba}$ \\
$27 \pm 1$ & 30 & $33,33 \mathrm{Ba}$ & $0,00 \mathrm{Bb}$ \\
\hline
\end{tabular}

${ }^{(1)}$ Médias seguidas de letras iguais, minúsculas nas linhas e maiúsculas nas colunas, não diferem pelo teste de Skott \& Snott, a $5 \%$ de probabilidade. de coloração nos embriões viáveis, o que interferiu nos padrões de coloração, em virtude da difusão do corante para embriões metabolicamente inativos. Segundo Valadares et al. (2009), a escolha de método adequado para o emprego do teste de tetrazólio em sementes ou embriões se baseia na facilidade para diferenciação de tecidos viáveis e inviáveis e na capacidade de diferenciar lotes de qualidade fisiológica distintas. Assim, a concentração de $0,01 \%$ de tetrazólio e o tempo de incubação de 18 horas foram eficientes para os objetivos deste trabalho.

Os resultados de coloração dos tecidos dos embriões foram isoladamente significativos quanto às condições e ao período de armazenamento (Tabela 2). A condição de armazenamento em $12 \%$ de umidade relativa do ar, associadaàtemperaturade $4 \mathrm{a}^{\circ} \mathrm{C}$, proporcionoumaiores percentagens de embriões viáveis, em comparação aos tratamentos armazenados na temperatura ambiente. O tempo de armazenamento de 30 dias apresentou as maiores médias de viabilidade, pois a temperatura alta e instável, comumente observada no ambiente, e o maior período de tempo, principalmente aos 120 dias, influenciou negativamente a conservação do fruto.

Em relação aos embriões parcialmente viáveis e inviáveis, os resultados foram significativos para interação entre condições ambientais e período de armazenamento. A maior percentagem de embriões

Tabela 2. Percentagem de embriões viáveis, parcialmente viáveis e não viáveis de oliveira 'Santa Catalina', após teste de tetrazólio, em diferentes condições de temperatura, umidade relativa do ar e períodos de armazenamento ${ }^{(1)}$.

\begin{tabular}{|c|c|c|c|}
\hline \multirow{2}{*}{$\begin{array}{l}\text { Temperatura } \\
\left({ }^{\circ} \mathrm{C}\right)\end{array}$} & \multirow{2}{*}{$\begin{array}{c}\text { Umidade relativa } \\
(\%)\end{array}$} & \multicolumn{2}{|c|}{ Período de armazenamento } \\
\hline & & 30 dias & 120 dias \\
\hline & & \multicolumn{2}{|c|}{ Embriões viáveis } \\
\hline 4 a 5 & 15 & $33,33 \mathrm{Aa}$ & $12,50 \mathrm{Aa}$ \\
\hline 4 a 5 & 12 & $33,33 \mathrm{Aa}$ & $12,50 \mathrm{Aa}$ \\
\hline $27 \pm 1$ & 55 & $0,00 \mathrm{Ba}$ & $0,00 \mathrm{Ba}$ \\
\hline \multirow[t]{2}{*}{$27 \pm 1$} & 30 & $20,00 \mathrm{Aa}$ & $12,50 \mathrm{Aa}$ \\
\hline & & \multicolumn{2}{|c|}{ Embriões parcialmente viáveis } \\
\hline 4 a 5 & 15 & $33,33 \mathrm{Aa}$ & $72,50 \mathrm{Aa}$ \\
\hline 4 a 5 & 12 & $43,33 \mathrm{Aa}$ & $58,33 \mathrm{Aa}$ \\
\hline $27 \pm 1$ & 55 & $59,52 \mathrm{Aa}$ & $16,66 \mathrm{Bb}$ \\
\hline \multirow[t]{2}{*}{$27 \pm 1$} & 30 & $66,66 \mathrm{Aa}$ & $58,33 \mathrm{Aa}$ \\
\hline & & \multicolumn{2}{|c|}{ Embriões não viáveis } \\
\hline 4 a 5 & 15 & $33,33 \mathrm{Aa}$ & $15,00 \mathrm{Ba}$ \\
\hline 4 a 5 & 12 & $23,33 \mathrm{Aa}$ & $29,16 \mathrm{Ba}$ \\
\hline $27 \pm 1$ & 55 & $40,48 \mathrm{Ab}$ & $83,33 \mathrm{Aa}$ \\
\hline $27 \pm 1$ & 30 & $13,33 \mathrm{Ab}$ & $33,33 \mathrm{Ba}$ \\
\hline
\end{tabular}

${ }^{(1)}$ Médias seguidas de letras iguais, minúsculas nas linhas e maiúsculas nas colunas, não diferem pelo teste de Skott \& Snott, a 5\% de probabilidade. 
parcialmente viáveis foi observada em $55 \%$ UR e $27 \pm 1^{\circ} \mathrm{C}$, aos 30 dias de armazenamento, seguido pelo tratamento $30 \%$ UR e $27 \pm 1^{\circ} \mathrm{C}$. A maior percentagem de embriões inviáveis foi observada para as condições de armazenamento com 55\% UR e $27 \pm 1^{\circ} \mathrm{C}$ após 120 dias $(83,33 \%)$, o que indica que este foi o pior tratamento.

Bernal-Lugo \& Leopold (1992) e Das \& Sen-Mandi (1992), ao trabalhar com sementes de algumas leguminosas, constataram que a exposição de sementes à temperatura e à umidade relativa elevadas provoca sérias alterações degenerativas no metabolismo das sementes, como desnaturação de proteínas, queda nos teores de carboidratos, desestabilização da atividade de enzimas, entre outros. Esses eventos são desencadeados principalmente pela desestruturação e pela perda da integridade do sistema de membranas celulares. Aparentemente, os embriões de oliveira estão sujeitos a esses mesmos sintomas.

De acordo com Nery et al. (2007), os decréscimos na viabilidade e no vigor das sementes podem ser atribuídos aos danos provocados nas membranas das mitocôndrias, o que acarreta redução da taxa respiratória aeróbica e da produção de energia na forma de ATP, que são imprescindíveis para o processo de germinação.

No teste de tetrazólio, os íons de $\mathrm{H}^{+}$liberados durante a respiração dos tecidos vivos são transferidos pela enzima desidrogenase do ácido málico, que interage com o tetrazólio. Como esta reação se processa no interior das células vivas e o composto não se difunde facilmente, há nítida separação dos tecidos vivos que respiram (corados de rosa), daqueles mortos, que não se colorem (Figura 1).

Foram observadas correlações positivas entre os dados médios para percentagem de germinação in vitro e os dados de percentagem de embriões viáveis e parcialmente viáveis, que foram obtidas pelo teste de tetrazólio nos diferentes tratamentos aplicados durante o armazenamento dos frutos de oliveira 'Santa Catalina' (Figura 2). A correlação linear entre os dados de germinação e os embriões viáveis foi melhor que a correlação linear obtida com os dados agrupados de embriões viáveis com os embriões parcialmente viáveis, o que pode ser explicado pelo fato de que nem todo embrião classificado como parcialmente viável foi capaz de germinar normalmente.

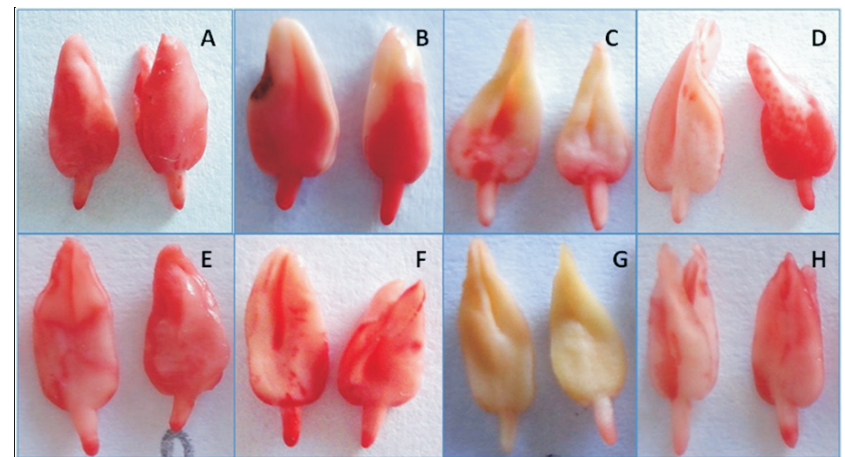

Figura 1. Coloração dos embriões de oliveira 'Santa Catalina' incubados por 18 horas em solução de tetrazólio a $0,01 \%$ aos 30 dias (A a D) e aos 120 dias (E a H). A, 4 a $5^{\circ} \mathrm{C}$ e $15 \%$ de umidade relativa (UR); $\mathrm{B}, 4$ a $5^{\circ} \mathrm{C}$ e $12 \%$ UR; C, $27 \pm 1^{\circ} \mathrm{C}$ e $55 \%$ de UR; D, $27 \pm 1^{\circ} \mathrm{C}$ e $30 \%$ UR; E, 4 a $5^{\circ} \mathrm{C}$ e $15 \%$ UR; F, 4 a $5^{\circ} \mathrm{C}$ e $12 \%$ UR; G, $27 \pm 1^{\circ} \mathrm{C}$ e $55 \%$ UR; $\mathrm{H}, 27 \pm 1^{\circ} \mathrm{C}$ e $30 \%$ UR. A, embriões viáveis; $\mathrm{B}$, embriões parcialmente viáveis; $\mathrm{C}$ e $\mathrm{G}$, embriões inviáveis.

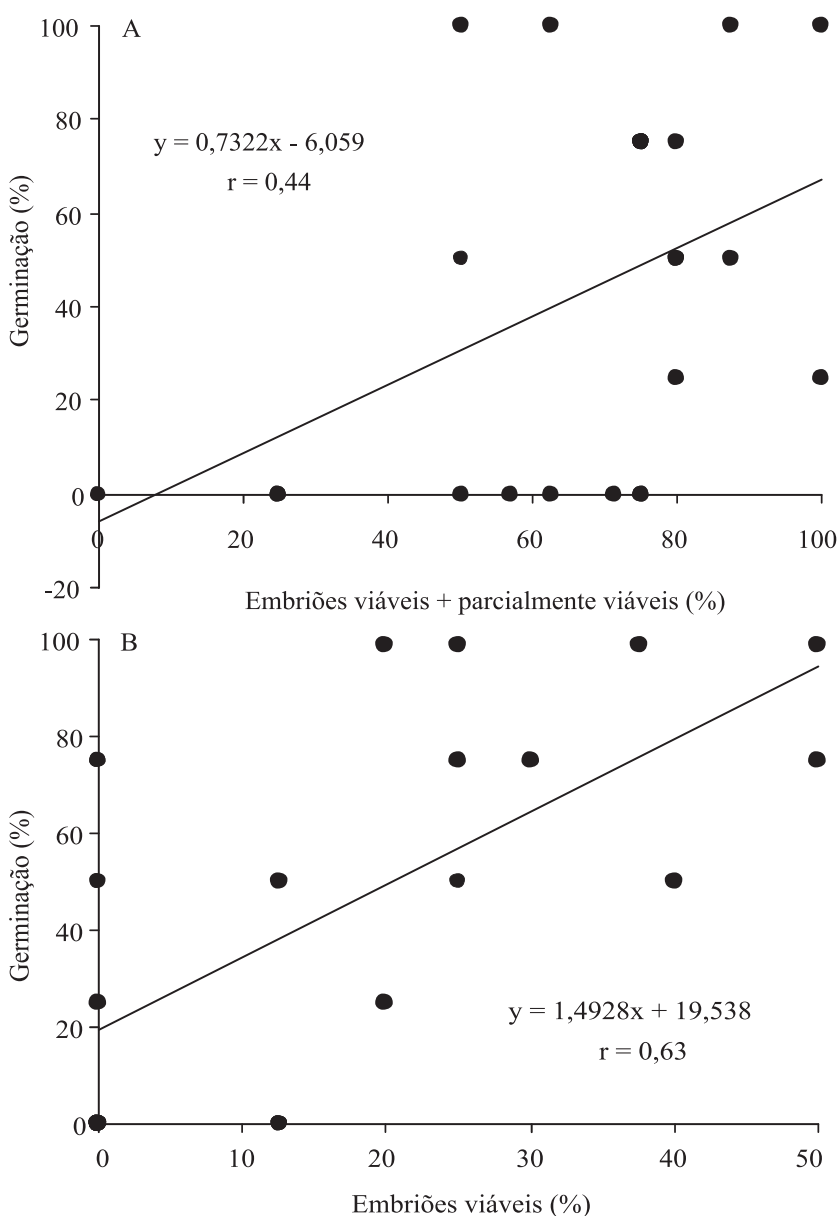

Figura 2. Correlação entre percentagem de germinação e embriões viáveis mais embriões parcialmente viáveis, A; correlação entre percentagem de germinação e embriões viáveis, B. 


\section{Conclusões}

1. O período de armazenamento de frutos de oliveira 'Santa Catalina' pode ser ampliado sem comprometer a germinação e a viabilidade dos embriões.

2. A melhor condição para o armazenamento de frutos de oliveira 'Santa Catalina' é em umidade relativa de $12 \%$ e temperatura de 4 a $5^{\circ} \mathrm{C}$.

\section{Agradecimentos}

À Fundação de Amparo à Pesquisa do Estado de Minas Gerais, à Coordenação de Aperfeiçoamento de Pessoal de Nível Superior, à Financiadora de Estudos e Projetos, e à Empresa Brasileira de Pesquisa Agropecuária, pelo apoio financeiro e pelas bolsas concedidas.

\section{Referências}

ALVAREZ-PARDO, V.; FERREIRA, A.G. Armazenamento de sementes de orquídeas. Revista Brasileira de Sementes, v.28, p.92-98, 2006.

BERNAL-LUGO, I.; LEOPOLD, A.C. Changes in soluble carbohydrates during seed storage. Plant Physology, v.98, p.1207-1210, 1992.

BINET, M.N.; LEMOINE, M.C.; MARTIN, C.; CHAMBON, C.; GIANINAZZI, S. Micropropagation of olive (Olea europaea L.) and application of mycorrhiza to improve plantlet establishment. In Vitro Cellular Developmental Biology Plant, v.43, p.473-478, 2007.

CARDOSO, P.C.; BAUDET, L.; PESKE, S.T.; LUCCA FILHO, O.A. Armazenamento em sistema a frio de sementes de soja tratadas com fungicida. Revista Brasileira de Sementes, v.26, p.15-23, 2004.
CARVALHO, M.L.M.; CAMARGO, R. Aspectos bioquímicos da deterioração de sementes. Informe Abrates, v.13, p.66-88, 2003.

DAS, G.; SEN-MANDI, S. Scuttelar amylase activity in naturally aged and accelerated aged wheat seeds. Annals of Botany, v.69, p.497-501, 1992.

DELOUCHE, J.C. Standardization of vigor tests. Journal of Seed Technology, v.1, p.75-85, 1976.

FERREIRA, D.F. Sisvar: um programa para análises e ensino de estatística. Revista Symposium, v.6, p.36-41, 2008.

MARCOS-FILHO, J. Fisiologia de sementes de plantas cultivadas. Piracicaba: Fealq, 2005. 495p.

MINISTÉRIO DA AGRICULTURA, PECUÁRIA E ABASTECIMENTO. Regras para análise de sementes. Brasília: Mapa, 2009. 399p.

MURASHIGE, T.; SKOOG, F. A revised medium for rapid growth and bioassays with tobacco tissue cultures. Physiologia Plantarum, v.15, p.473-479, 1962.

NERY, M.C.; CARVALHO, M.L.M. de; OLIVEIRA, L.M. de. Teste de tetrazólio para avaliação da qualidade fisiológica de sementes de melancia. Semina: Ciências Agrárias, v.28, p.365-372, 2007.

OLIVEIRA, A.F. Enraizamento de estacas semi-lenhosas e cultura de embriões in vitro de oliveira (Olea europaea L.). 2001. 122p. Tese (Doutorado) - Universidade Federal de Lavras, Lavras.

OLIVEIRA, L.M. de; CARVALHO, M.L.M. de; DAVIDE, A.C. Teste de tetrazólio para avaliação da qualidade de sementes de Peltophorum dubium (sprengel) taubert leguminosae caesalpinioideae. Cerne, v.11, p.159-166, 2005.

ROUSSOS, P.A.; PONTIKIS, C.A. In vitro propagation of olive (Olea europaea L.) cv. Koroneiki. Plant Growth Regulation, v.37, p.295-304, 2002.

VALADARES, J.; DE PAULO, R.C.; MORO, F.V. Germinação, desenvolvimento de plântulas e teste de tetrazólio em Poecilanthe parviflora Bentham (Fabaceae - Faboideae). Científica, v.37, p.39-47, 2009.

VIEIRA-NETO, J.; OLIVEIRA, A.F. de; OLIVEIRA, N.C. de; DUARTE, H. da S.S.; GONÇALVES, E.D. Aspectos técnicos da cultura da oliveira. Belo Horizonte: Epamig, 2008. 56p. (Epamig. Boletim técnico, 88).

Recebido em 27 de setembro de 2010 e aprovado em 31 de janeiro de 2011 